RESENHA

Bookreview

\title{
STATE-BUILDING IN BOOM TIMES: COMMODITIES AND COALITIONS IN LATIN AMERICA AND AFRICA ${ }^{1}$
}

Rogerio Makino ${ }^{2}$

O que explica os diferentes graus de desenvolvimento entre os países em desenvolvimento? Um dos conceitos que ganhou notoriedade nos estudos comparados de desenvolvimento e naqueles sobre as relações entre Estado e desenvolvimento, nessas últimas décadas, principalmente a partir da ascensão da perspectiva institucionalista, é o de capacidade estatal, isto é, "a capacidade de penetrar a sociedade civil e implementar logisticamente decisões políticas em toda a sua jurisdição" (Saylor, 2013, p. 2). A capacidade estatal ou o conjunto de instituições estatais efetivas passou a ser entendida como uma condição necessária, mas não suficiente, para um Estado fazer valer as suas leis e normativas, prover bens públicos e implementar políticas públicas efetivas, além de ser considerado um pré-requisito para a transformação econômica.

No que se refere aos países em desenvolvimento, especialmente àqueles com as economias voltadas à exportação, um dos "mitos" mais disseminados e persistentes é o da "maldição dos recursos naturais" ou "doença holandesa", a saber, a suposta tendência dos países abastados em recursos naturais em sofrer impactos negativos em outros setores da economia e na esfera política. Nessa perspectiva, existiria uma propensão

\footnotetext{
${ }^{1}$ SAYLOR, Ryan. State Building in Boom Times: Commodities and Coalitions in Latin America and Africa. Oxford: Oxford University Press, 2014. ISBN: 978-0199364954

${ }^{2}$ Doutorando em Ciências Sociais CEPPAC/UnB e Mestre em Relações internacionais IREL/UnB. Email: makinotga@yahoo.com.br
} 


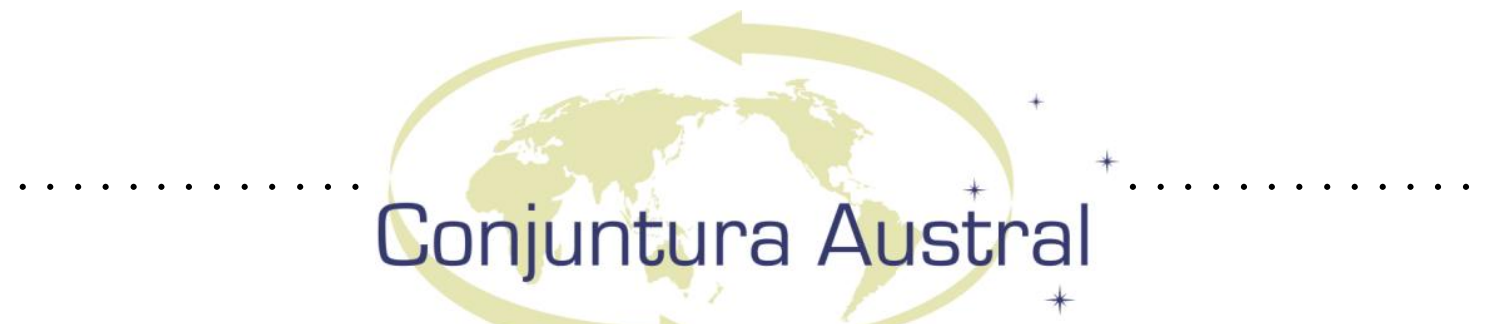

para que esses Estados desenvolvessem instituições extrativas diante da "riqueza fácil" e ficassem mais vulneráveis aos interesses particularistas, à corrupção e ao rent-seeking de modo a causar um efeito negativo sobre a sua capacidade estatal.

Ryan Saylor ${ }^{3}$ lança dúvidas acerca da leitura acima e defende em seu livro que nem a vastidão de recursos naturais nem a dependência da exportação de commodities específicas são capazes de explicar a baixa capacidade estatal e o consequente subdesenvolvimento. A tese do autor é que o efeito positivo ou negativo sobre a capacidade estatal depende da composição da coalizão política que governa o país. Quando os agentes econômicos envolvidos nas atividades relacionadas a essas riquezas naturais ou a produção de commodities (mineradores, produtores, exportadores, etc) fazem parte da coalizão ou da elite governante, a tendência é de um efeito positivo na capacidade estatal. Isso ocorre principalmente em função da vigilância em torno do direcionamento dos recursos arrecadados pelo Estado, da reversão deles sob a forma de provisão de bens públicos e da luta redistributiva intrínseca ao próprio jogo político. $\mathrm{Na}$ contramão, quando a coalizão governante marginaliza politicamente os agentes econômicos dinâmicos, a tendência em âmbito de Estado, é a oposta, isto é, pilhagem e clientelismo (Saylor, 2013, p. 7).

Saylor testa a sua hipótese analisando seis casos de países latino-americanos e africanos em momentos de expansão das exportações (boom times): cobre e trigo chileno (1848-1883); lã argentina (1852-1886); açúcar mauriciano (1825-1896); café colombiano (1880-1905); cacau ganense (1945-1966); e produtos agrícolas nigerianos (1945-1966). No que se refere à construção de capacidade estatal, os três primeiros, que incluíram na coalizão governante os agentes econômicos dinâmicos, seriam casos de sucesso e os três últimos, que os marginalizaram, de fracasso.

No passado, trabalhos como os de Sachs \& Warner (1997), que investigaram alguns países africanos, encontraram evidências que corroboraram com a existência, em

\footnotetext{
${ }^{3}$ Ryan Saylor é graduado em Diplomacia e Assuntos Estrangeiros pelo Universidade de Miami, mestre em Assuntos Estrangeiros pela Universidade de Virgínia e Doutor (Ph.D.) em Assuntos Estrangeiros pela Universidade da Virgínia. Suas áreas de interesse para pesquisa são metodologia qualitativa, statebuilding, desenvolvimento político e políticas de desenvolvimento de países em desenvolvimento (especialmente África e América Latina).
} 


\section{Conjuntura Austral}

alguma medida, da "maldição dos recursos naturais". ${ }^{4}$ A pesquisa de Saylor traz mais uma variável - a das coalizões e a da inclusão política - para matizar tal teoria e para ajudar a compreender a complexa questão da construção da capacidade estatal e, com efeito, os processos de desenvolvimento e as diferenças nesse quesito entre os países. A ideia central do livro está em consonância com outras obras recentes como Acemoglu \& Robinson (2012), que sem analisar especificamente a questão da capacidade estatal, defendem que a chave do sucesso dos países desenvolvidos é a combinação de instituições inclusivas (possibilidade de participação da maioria e, idealmente, de todos) nas esferas econômica e política. Nesse sentido, a contribuição do livro para o debate institucionalista do desenvolvimento é fazer uma ponte entre a questão da participação ampliada (instituições inclusivas) e a capacidade estatal cujo potencial cada vez mais tem sido entendido como um pré-requisito para um bom desempenho econômico.

\section{Referências}

ACEMOGLU, Daron; ROBINSON, James A.; WOREN, Dan. Why nations fail: the origins of power, prosperity, and poverty. New York: Crown Business, 2012.

SACHS, Jeffrey D.; WARNER, Andrew M.The curse of natural resources. European economic review, v. 45, n. 4, p. 827-838, 2001.

SACHS, Jeffrey D.; WARNER, Andrew M. Natural resource abundance and economic growth.(Working $\quad$ Paper) $1997 . \quad$ Disponível em: http://academiccommons.columbia.edu/catalog/ac:138842

Resenha recebida em 08 de agosto de 2014. Aprovada em 22 de agosto de 2014.

\footnotetext{
${ }^{4}$ Em trabalhos mais recentes, como Sachs \& Warner (2001), essa teoria é matizada.
} 